\title{
Watershed sediment source identification: tools, approaches, and case studies
}

\author{
Allen C. Gellis • Rajith Mukundan
}

Received: 28 August 2013 / Accepted: 6 September 2013 / Published online: 24 September 2013

(C) Springer-Verlag (outside the USA) 2013

Many of us who have watched a stream turn turbid during a rainstorm have often wondered-where is all that sediment coming from? Geomorphologists, engineers, and environmental scientists have thought about this question for decades and have placed understanding sediment sources under the general framework of sediment budgets. This framework which examines not only sediment sources but the storage, transport, and delivery of sediment has been used to understand surficial processes, as well as address management concerns as they relate to stream turbidity and surface-water quality. Traditional tools used in sediment budgets have included field measurements of erosion, storage and transport rates, photogrammetric analysis, and modeling. The relationship between soil erosion and sediment yield at the watershed outlet has been long identified as a major research need (Walling 1983) and is still a poorly understood or misunderstood component of fluvial sediment transport (Kinnell 2004). In recent decades, sediment fingerprinting approaches using the geochemical and physical properties of sediment to determine sediment sources have become increasingly popular.

This special issue on Watershed Sediment Source Identification, for the Journal of Soils and Sediments was produced as a result of a special session convened at the Association of American Geographers (AAG) 2012 annual meeting in New York City, NY, USA. The session was entitled "Watershed Sediment Source Identification" and brought together leading

\footnotetext{
A. C. Gellis $(\bowtie)$

U.S. Geological Survey, 5522 Research Park Drive, Baltimore, MD 21228, USA

e-mail: agellis@usgs.gov

R. Mukundan ( $₫)$

Institute for Sustainable Cities, City University of New York, New York, NY, USA

e-mail: Rajith.Mukundan@hunter.cuny.edu
}

experts in the field of sediment sourcing. As a result of the AAG session, the Journal of Soils and Sediments offered to have the session and a few other papers on the same topic published as a special issue in the journal. This special issue reflects contributions from 29 researchers discussing sediment sourcing results from studies in Africa, Asia, Europe, and North America where settings range from urban to agricultural to forested.

Sediment source assessment is not only important to our understanding of sediment dynamics in fluvial systems but is increasingly becoming an important management tool. The papers in this special issue reflect a range of studies that address both topics. Studies emphasize traditional field approaches to determine sediment yields and sources (Davis and Sims 2013; Zhu 2013) as well as the use of the sediment fingerprinting approach to determine significant sediment sources (Dutton et al. 2013; Gellis and Noe 2013; Huisman et al. 2013; Koiter et al. 2013; Mckinley et al. 2013; Voli et al. 2013). Several papers highlight site-specific methods and approaches to streamline the sediment fingerprinting approach into a practical management tool. Other papers relate findings from sediment fingerprinting to hydrologic conditions, and caution users on over-interpreting the sediment fingerprinting results.

Walling (2013), in the opening paper, provides a history on the sediment fingerprinting approach and illustrates how publications on the subject have increased exponentially since the 1970s. A review of these publications indicate that many studies have used sediment fingerprinting to determine sediment sources as a means to improve our understanding of erosion and sediment delivery processes. Other papers use sediment fingerprinting as a management tool. Walling (2013) lists key advances in the sediment fingerprinting approach over the last 30 years that include the use of multiple or composite fingerprints, statistical tests and models, size and organic correction factors, increased source and target assessments, and improved estimates of uncertainty. Given these advances in the sediment 
fingerprinting approach, Walling (2013) suggests that improvements can still be made with respect to establishing guidelines in choosing the best sediment properties for sediment sourcing. Identification of the most robust statistical procedures and the use of mixing models are also seen as key components of the sediment fingerprinting approach that could benefit by establishing guidelines.

Six papers in this special issue describe the use of the sediment fingerprinting approach to determine suspended sediment sources in watersheds. In an agricultural watershed in the Canadian prairies, Koiter et al. (2013) was able to discriminate between three sources - top soil, streambanks, and shale bedrock-using four fingerprint properties. Sediment source varied with respect to location in the basin, where important sediment sources in the upper reaches were dominated by topsoil sources while the streambanks and shale bedrock were more important sources in the lower portions of the watershed. Their paper highlights the importance of source sampling locations, scale, and connectivity of the sources to the results derived from sediment fingerprinting.

Voli et al. (2013) describes results of a study using the sediment fingerprinting approach in four watersheds draining to a municipal water supply reservoir of the Neuse River, North Carolina, USA, that was faced with turbidity problems. Six sediment sources were identified and their relative contribution was determined using 57 fingerprint properties. In three of the four watersheds investigated, streambank erosion was the largest contributor of sediment with active construction sites and timber harvesting also being important sediment sources. Highlights from this paper include use of a modified time-integrated sediment samples from the design of Phillips et al. (2000), emphasis on particle size correction of tracer data using $\mathrm{D}_{50}$ (median particle size), and use of Monte Carlo sampling to account for uncertainty in mixing model results.

An improved method to collect the necessary mass for sediment fingerprinting was highlighted in the paper by Dutton et al. (2013). Faced with collecting suspended sediment in a remote area of Kenya, Africa, the authors utilized sediment-laden filters to obtain river samples. The use of these filters allowed flow-weighted samples to be collected, processed, and analyzed. Sources were separated into geographic region. Hippopotamus feces were identified as a small, but measurable, proportion of sediment in this system. Another highlight of this paper is the use of Stable Isotope Analysis in R (SIAR) mixing model with Bayesian inference to account for uncertainty in sediment source apportionment which is also described in Koiter et al. (2013).

In the paper by Huisman et al. (2013), the sediment fingerprinting approach is used to identify important sources of sediment and sediment-bound phosphorus in the North Fork of the Pheasant Branch watershed, Wisconsin, USA. Radionuclides and phosphorus were used to discriminate the potential contributions from cultivated lands, streambanks, and streambeds. Cultivated land showed to be the most important source of sediment. The authors use a combination of longlived $\left({ }^{210} \mathrm{~Pb}_{\mathrm{xs}}\right)$ and short-lived $\left({ }^{7} \mathrm{Be}\right)$ radioisotopes to determine the age of streambed and suspended sediment using the method described in Matisoff et al. (2005). The application of isotopes to sediment sourcing is an important area of research that needs further attention.

Fine-grained sediment is an important pollutant in many water bodies throughout the world and identifying the important sources of sediment is necessary to reducing sediment loadings. In the Chesapeake Bay and its tributaries in the USA, fine-grained sediment is a major contributor to habitat degradation. Gellis and Noe (2013) examine sediment sources in the Linganore Creek Watershed, MD, USA, which drains the highest sediment yield region of the Chesapeake Bay watershed, the Piedmont. Using 23 tracers, streambanks and cultivated land were found to contribute the most fine-grained sediment. Sources from streambanks occurred during high flows and in winter months. Gellis and Noe caution researchers not to over-interpret sediment fingerprinting results on a stormby-storm basis. Because sediment fingerprinting results do not include the temporal aspects of the sourced sediment, sediment that is in storage from previous events may be remobilized and sampled during the current event and will reflect previous storm characteristics. By averaging sediment sources over several storms, it may be possible to determine not only the sediment sources that are directly contributed from the current event but sediment from previous events that was in storage and remobilized.

The importance of streamlining the sediment fingerprinting approach into a management tool is presented in McKinley et al. (2013) with emphasis on the total maximum daily load program, a regulatory framework of the US Environmental Protection Agency. The streamlined approach was tested in the North Fork Broad River, Southern Piedmont Region of Georgia, USA, using results from a previous sediment source study. A tracer suite that could adequately identify sediment sources was identified for the Southern Piedmont and resulted in considerable cost savings. McKinley et al. (2013) also show that an automatic suspended sediment sampler provides comparable results to the more expensive continuous-flow centrifuge which was used in the previous study.

In two other papers, traditional sediment budget approaches to understand sediment processes are presented. Zhu (2013) examines open-plot studies in the highly erosive Loess Plateau of China to show how landscape position, soil type, and tunnel erosion (piping) influence runoff and sediment yields. Open plots are shown to be preferable to closed plots. Concerned about the impact of urbanization on salmon habitat in California, Davis and Sims (2013) employs field surveys, photogrammetry, and GIS models to understand hill slope sediment sources. Landslides and gullies that were mapped are a function of land use changes that have occurred 
in agricultural and residential lands over time. Such approaches that use monitoring and mapping still offer important information about predetermined sediment sources.

Sediment is a global pollutant degrading aquatic habitat and public water supplies. We expect that as the science to determine watershed sources of sediment improves and becomes practical, our ability to restore these degraded habitats may improve. While we regard this special issue as a snapshot of the state-of-the science on sediment sourcing, there are a number of key challenges/areas that need further attention/research while using these techniques to understand sediment processes or as a sediment management tool. These include:

- Selecting the best suite of conservative tracers for a region and developing well-defined protocols that incorporate a standard particle size and organic matter correction to sediment tracer property values used to characterize both sources and targets

- Accounting and quantifying the sediment deposited in the channel from previous events when interpreting sediment fingerprinting results on a storm-by-storm basis

- Choosing the best statistical procedure for sediment source apportionment that also takes into consideration various sources of uncertainty in the analysis

- Using short-term studies to understand long-term sediment transport dynamics

- Determining the importance of source sampling locations, scale, and connectivity of the sources on the results derived from sediment fingerprinting

\footnotetext{
Acknowledgments We would like to extend our appreciation to Phil Owens and Moira Ledger who made this special issue possible. We also want to thank the authors who contributed to the special issue and to the reviewers whose constructive and timely reviews were essential in producing a quality publication.
}

\section{References}

Davis J, Sims S (2013) Physical and maximum entropy models applied to inventories of hillslope sediment sources. J Soils Sediments. doi:10. 1007/s11368-013-0774-3 (this issue)

Dutton C, Anisfeld SC, Ernstberger H (2013) A novel sediment fingerprinting method using filtration: application to the Mara River East Africa. J Soils Sediments. doi:10.1007/s11368-013-0725-z (this issue)

Gellis AC, Noe GB (2013) Sediment-source analysis in the Linganore Creek Watershed, Maryland using the sediment-fingerprinting approach: 2008 to 2010. J Soils Sediments. doi:10.1007/s11368-013-0771-6 (this issue)

Huisman NLH, Karthikeyan KG, Lamba J, Thompson AM, Peaslee G (2013) Quantification of seasonal sediment and phosphorus transport dynamics in an agricultural watershed using radiometric fingerprinting techniques. J Soils Sediments. doi:10.1007/s11368-013-0769-0 (this issue)

Kinnell PIA (2004) Sediment delivery ratios: a misaligned approach to determining sediment delivery from hillslopes. Hydrol Process 18:3191-3194

Koiter AJ, Lobb DA, Owens PN, Petticrew EL, Tiessen KHD, Li S (2013) Investigating the role of connectivity and scale in assessing the sources of sediment in an agricultural watersheds in the Canadian prairies using sediment source fingerprinting. J Soils Sediments. doi: 10.1007/s11368-013-0762-7 (this issue)

Matisoff G, Wilson CG, Whiting PJ (2005) The Be-7/PB210(xs) ratio as an indicator of suspended sediment age or fraction new sediment in suspension. Earth Surf Proc Land 30:1191-1201

McKinley R, Radcliffe D, Mukundan R (2013) A streamlined approach to sediment source fingerprinting in a Southern Piedmont watershed, USA. J Soils Sediments. doi:10.1007/s11368-013-0723-1 (this issue)

Phillips JM, Russell MA, Walling DE (2000) Time-integrated sampling of fluvial suspended sediment: a simple methodology for small catchments. Hydrol Process 14:2589-2602

Voli MT, Wegmann KW, Bohnenstiehl DR, Leithold EL, Osburn CL, Polyakov V (2013) Fingerprinting the sources of suspended sediment delivery to a large municipal drinking water reservoir: Falls Lake, Neuse River, North Carolina, USA. J Soils Sediments. doi:10. 1007/s11368-013-0758-3 (this issue)

Walling DE (1983) The sediment delivery problem. J Hydrol 65:209-237

Walling DE (2013) The evolution of sediment source fingerprinting investigations in fluvial systems. J Soils Sediments. doi:10.1007/s11368-0130767-2 (this issue)

Zhu T (2013) Spatial variation and interaction of runoff generation and erosion within a semi-arid, complex-terrain catchment: a hierarchical approach. J Soils Sediments. doi:10.1007/s11368-013-0760-9 (this issue) 